\title{
A correctable cause of lung collapse in an adolescent with severe scoliosis causing compression of the bronchial tree
}

\author{
Pierre Goussard, ${ }^{1}$ Robert Gie, ${ }^{2}$ Savvas Andronikou, ${ }^{3}$ Pieter Rousseau Fourie ${ }^{4}$
}

'Department of Paediatrics, Stellenbosch University, Cape Town, South Africa

${ }^{2}$ Department of Child Health and Pediatrics, Stellenbosch University, Cape Town, South Africa

${ }^{3}$ Department of Radiology, University of the

Witwatersrand, Johannesburg, South Africa

${ }^{4}$ Department of Critical Care and Anaesthesia, Stellenbosch University, Cape Town, South Africa

\section{Correspondence to} Dr Pierre Goussard, pgouss@sun.ac.za

\section{DESCRIPTION}

A 17-year-old boy with known severe cerebral palsy presented with cough, fever and shortness of breath. He was a spastic quadriplegic with muscle weakness, severe scoliosis and poor cough which made it difficult for him to clear respiratory secretions. He presented with acute pneumonia which resulted in progressive respiratory failure requiring intubation and ventilation. The initial plain chest radiograph (figure 1A) demonstrated severe scoliosis and mediastinum shift to the right. On following the airways an abrupt cut-off of bronchus intermedius at the level where it crossed the vertebral column was seen. This resulted in a collapse of the right middle and lower lobes, further compromising the respiratory compromise. On X-ray, the curve measured $107^{\circ}$ according to the Cobb method.

Fibre-optic bronchoscopy demonstrated compression of the bronchus intermedius from the posterior with an almost complete occlusion of the bronchus intermedius. The left bronchial tree was normal. A chest CT scan (figure 2A,B) confirmed the narrow chest (decreased diameter between the anterior thoracic wall and the vertebral bodies), a mediastinum shifted to the right and a compressed bronchus intermedius. As a result of the scoliosis, the bronchus intermedius had a horizontal rather than vertical orientation, with the bronchus narrowing caused by stretching of the bronchus across the vertebral body. The collapsed right middle and lower lobes are clearly visible. Bronchial lavage and chest physiotherapy failed to resolve the collapsed lobes. The patient underwent a long posterior correction with fusion, instrumentation from the level of $\mathrm{T} 2$ to the pelvis and multiple osteotomies for the severe scoliosis and had an uncomplicated postoperative course. Spinal radiographs (figure 1B) obtained postoperatively demonstrated that the collapsed lobes had re-expanded.

Respiratory compromise is a well-recognised complication of children with cerebral palsy. Most

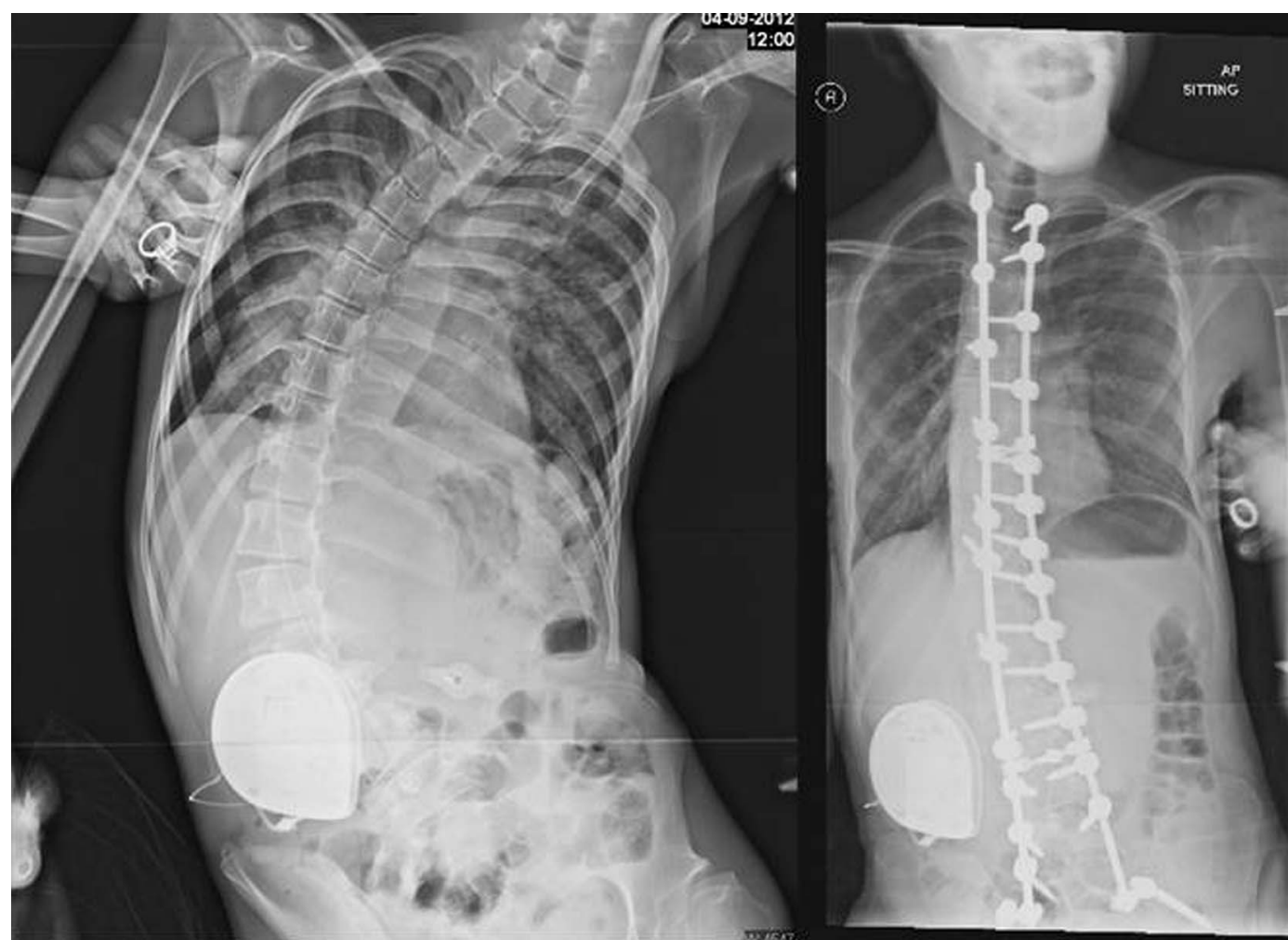

Figure 1 (A) Preoperative plain radiographs of the spine demonstrate scoliosis concave to the right with severe obstruction of the bronchus intermedius and collapse of the right middle and lower lobes. (B) Postoperative spine radiograph demonstrates the dual rod, segmental spinal-fixation system, the improved spinal curvature. The hemithoraces are of comparable volumes and densities, and the areas of collapse in the right lung have resolved. (The airway is not clearly visualised.) 


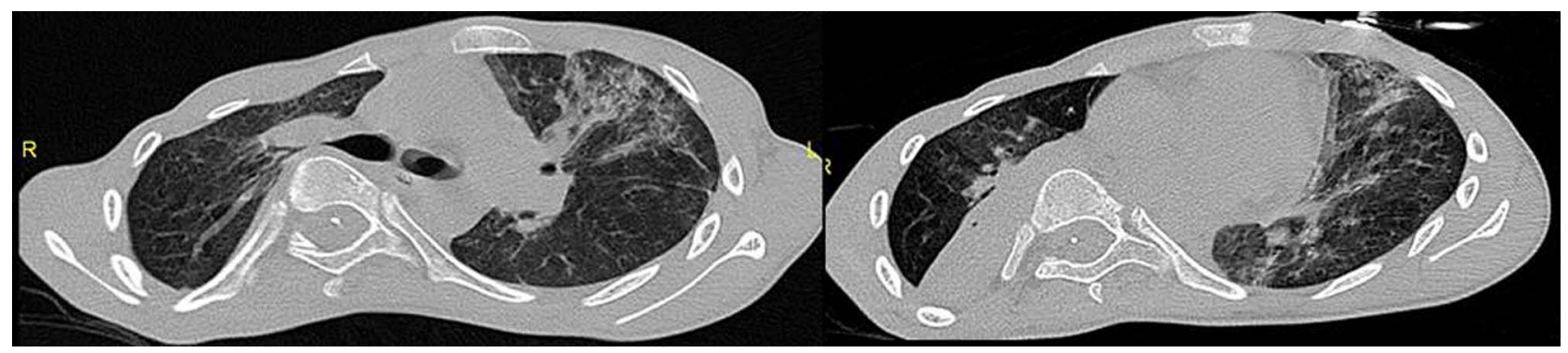

Figure 2 (A and B) Non-sequential axial CT scans of the chest on 'lung window' demonstrate a narrow anteroposterior dimension of the chest and abnormal spinal configuration leading to mediastinal displacement to the left. The severe narrowing of the bronchus intermedius is seen in (A) as the bronchus passes over the vertebral body (arrow) and the resultant lung collapse is seen on the right adjacent to the vertebral body in (B). There is also compensatory hyperinflation of the upper lobe on the right and patchy airspace disease on the left with decreased lung volume.

recurrent chest infections are ascribed to repeated aspiration. Severe scoliosis leads to chest wall deformity which further decreases lung function and increases the risk of lower respiratory tract infections. Torsion of the large airways in children with lordoscoliosis may lead to bronchial compression. ${ }^{1} 2$ This problem is possibly more common than previously recognised and may be the explanation for the higher incidence of empyema and lung abscesses in these children. ${ }^{3}$ Ventilation to the lung and clearance of secretions can be re-established if the thoracic lordoscoliosis is successfully surgically repaired.

\section{Learning points}

- Torsion of the large airways in children with lordoscoliosis may lead to bronchial compression.

- Bronchial compression may improve if surgery is performed for thoracic lordoscoliosis.

- Children with cerebral palsy and thoracic lordoscoliosis are at high risk for respiratory complications.
Contributors $P G$ and RG were involved in writing the manuscript and were the consultant physicians in managing the patient. SA read and interpreted the X-rays and CT scan of the chest. PRF was the paediatrician who treated the patient.

Competing interests None.

Patient consent Obtained.

Provenance and peer review Not commissioned; externally peer reviewed.

\section{REFERENCES}

1 Barlett W, Garrido E, Wallis C, et al. Lordoscoliosis and large intrathoracic airway obstruction. Spine 2009;34:59-65.

2 Tatekawa Y, Tojo T, Kanehiro H, et al. Multistage approach for tracheobronchomalacia caused by a chest deformity in the setting of severe scoliosis. Surg Today 2007;37:910-14.

3 Schena S, Krupnick AS. Recurrent empyema secondary to persistent spinal compression of the left main bronchus. J Thorac Cardiovasc Surg 2013;145:294.

Copyright 2013 BMJ Publishing Group. All rights reserved. For permission to reuse any of this content visit http://group.bmj.com/group/rights-licensing/permissions.

BMJ Case Report Fellows may re-use this article for personal use and teaching without any further permission.

Become a Fellow of BMJ Case Reports today and you can:

- Submit as many cases as you like

- Enjoy fast sympathetic peer review and rapid publication of accepted articles

- Access all the published articles

- Re-use any of the published material for personal use and teaching without further permission

For information on Institutional Fellowships contact consortiasales@bmjgroup.com

Visit casereports.bmj.com for more articles like this and to become a Fellow 